Research Paper:

\title{
Investigation of Risky Behavior Among Iranian Medical Students Based on Demographic Characteristics
}

\author{
Amir Keshavarzi $^{1}$ (D), Marzieh Nazaribadie ${ }^{1^{*}}$ (D), Mohammad Ahmadpanah ${ }^{1}$ (D) Ali Ghaleiha ${ }^{1}$ if
}

1. Research Center for Behavioral Disorders and Substance Abuse, Hamadan University of Medical Sciences, Hamadan, Iran.

\begin{tabular}{l|l}
$\begin{array}{c}\text { Use yourdevice toscan } \\
\text { and read the article online }\end{array}$ & $\begin{array}{l}\text { Citation Keshavarzi A, Nazaribadie M, Ahmadpanah M, Ghaleiha A. Investigation of Risky Behavior Among Iranian Medi- } \\
\text { cal Students Based on Demographic Characteristics. Avicenna J of Neuropsychophysiology. 2017; 4(3):121-128. http://dx.doi. } \\
\text { org/10.32598/ajnpp.4.3.121 }\end{array}$ \\
doi'http://dx.doi.org/10.32598/ajnpp.4.3.121
\end{tabular}

\section{(i) $\$$}

Article info:

Received: 05 Jan 2017

Accepted: 28 Jun 2017

Available Online: 01 Aug 2017

Keywords:

Risky behaviors, Demographic characteristics, Students

\section{A B STRACT}

Introduction: The likelihood of doing risky behavior such as drug use, high-risk sexual behavior, and adjustment problems in youth period is high. The present study aimed to investigate the prevalence of risky behaviors among first-year medical students.

Objectives: In this research, we intend to study the extent of risk behaviors based on demographic variables among medical students of Hamadan.

Materials and Methods: This cross-sectional study was carried out on all first-year medical students (498 females and 292 males) of Hamadan University of Medical Sciences in the academic year 2016-2017. The study data were collected by the Iranian Youth Risk-Taking Scale (IYRTS).

Results: The mean scores of risky driving (2.86) (53.60\%) and sexual relationship/attitude (2.43) $(48.60 \%)$ were higher than other high-risk behaviors while the mean scores of drug use (1.33) (26.60\%) and drinking (1.57) (31.40\%) were lower than other risky behaviors in medical students. Results of the Chi-square test indicated that the risky behaviors in males were significantly higher than those in females $(P<0.05)$. The results of 1 -sample t-test indicated that the prevalence of risky driving, violence, smoking, drug use and drinking in Hamadan medical students is less than average, and the sexual relationship and attitude among these students is at moderate level $(P>0.05)$. The relationship between age and education with risky driving was negative and statistically significant. The violence was positively related to drinking and smoking. The sexual relation, attitude, and drinking statically significant.

Conclusion: Since some sorts of risky behaviors among students are prevalent, it seems logical to inform adolescents and youth about such high-risk behaviors and related health issues.

* Corresponding Author: 


\section{Introduction}

ran's population is young. It is estimated that $60 \%$ of its population is between 20 and 25 years old. During the youth period, the likelihood of doing risky behaviors such as substance use, high-risk sexual behaviors, and adjustment problems is high [1]. Engaging in such risky behaviors during can be problematic and result in many negative consequences, e.g. alcohol dependence and early pregnancy [2, 3]. A great concern of the international community is the onset of HIV epidemic that can devastate families, communities, and nations worldwide [4].

Youth violence is a significant public health problem and recently the rate of violence has increased in the communities [5]. Risky driving behaviors are common among young people, particularly among young males $[6,7]$. Drunk drivers contribute significantly to road traffic injuries [8, 9]. Some studies have shown that most risky behaviors such as smoking, alcohol consumption, substance abuse, and unsafe sexual behaviors begin before the age of 18 [10].

In a longitudinal study in the United States, ten highrisk behaviors, including tobacco use, persistent alcohol consumption, being permanently drunken, substance abuse, physical conflicts, suicidal thoughts, unsuccessful suicide attempts, and unprotected sexual inter courses were investigated in students. Their findings indicated that the prevalence of physical conflicts in all groups was higher than other behaviors, and male students were generally more likely to be involved in a variety of risky behaviors than female students except for suicidal ideation which was higher in girls [11].

If the risk-taking behavior of the youth is understood and considered a normal growing process, not deviant and criminal behavior, preventing the violence and risky behaviors in adolescents and youth will be more feasible. On the other hand, there are many commonalities between the risk-taking and the criminal tendencies of the young people, and unless necessary measures are taken to prevent such maladaptive behaviors, youth will gradually commit serious crimes by making seemingly simple mistakes. The duty of the judicial system will become more difficult by overlooking this issue.

According to previous studies, because of the rapid changes in society, school and university students have now gotten involved in high-risk behaviors more than ever. Now, the necessary tools are mandatory to recog- nize the risky behaviors of university students. High-risk behaviors have many negative consequences, including psychological diseases like depression; physical diseases like AIDS and sexually transmitted diseases; and social problems like school drop-out, academic, and occupational failure. In recent years, the prevalence of risky behaviors among adolescents and youth has turned into a social dilemma.

Lack of accurate information about their health needs impedes the planning of a specific health program for the young. Thus, conducting such a study can provide useful information on the prevalence of high-risk behaviors for authorities and higher education planners. The prevalence of high-risk behaviors among students in Iran has not been studied and most previous related studies have focused on adolescence group. In this research, we aimed to study the extent of risk behaviors among first-year medical students of Hamadan University based on demographic characteristics.

\section{Materials and Methods}

A cross-sectional study was carried out in all newlyadmitted students (498 females and 292 males) of Hamadan University of Medical Sciences in 2016-2017 academic year. The study samples were recruited from all students of Hamadan University of Medical Sciences by using convenience sampling method. First, a list of new students was obtained from the university. Then, demographic variables and high-risk questionnaires were completed by all new students. The informed consent was obtained from all individuals participated in the study.

The only exclusion criterion was being a guest student from other universities. The self-administered Iranian Youth Risk-Taking Scale (IYRTS) was used for assessing risky behavior, and demographic variables were also recorded in a separate sheet. The study was approved by the Ethics Committee of Hamadan University of Medical Sciences (No.: IR.UMSHA.REC.1395.414). Written consent was taken from each student.

\section{High-Risk Behaviors Scale}

The self-administered Iranian Youth Risk-Taking Scale (IYRTS) has 34 items for assessing the vulnerability of adults to six categories of high-risk behaviors, including risky driving, violence, smoking, drug use, drinking, sexual relationship, and behavior attitudes. This 5-point Likert-type scale is scored from 5 (strongly agree) to 1 (strongly disagree). The construct valid- 
ity of the IYRTS was evaluated by exploratory factor analysis. The results showed that the validity of IYRTS and its subscales is appropriate. The Cronbach alpha obtained for total scale was 0.93 and separately for the subscales were 0.88 for risky driving, 0.91 for smoking, 0.83 for drug use, 0.93 for drinking, 0.85 for sexual relationship behavior, and 0.77 for violence. The results proved the validity of the scale [12].

The obtained data were analyzed using descriptive statistical analysis like frequency and percentage and inferential statistical analysis, including t-test and correlation coefficient. At the end of the study, the data collected were re-entered into particular forms and analyzed in SPSS 21.

\section{Results}

A total of 790 individuals participated in this study. Out of them, 292 were men and 498 were women. The Mean \pm SD age of the participants was $22 \pm 5$ years. According to Table 1, the mean scores of risky driving (2.86) and sexual relationship and attitude (2.43) are higher than other high-risk behaviors, while the mean scores of drug use (1.33) and drinking (1.57) are lower than other risky behaviors in medical students.

As shown in the Table 2, the prevalence rates of risky high driving among male and female students were $18.20 \%$ and $12.7 \%$, respectively. In contrast, the percentage of slightly risky driving was lower in girls (19.2\%) than in boys (15.7\%). The percentages of sexual relationship and attitude were $7.60 \%$ and $1.8 \%$ in boys and girls, respectively. While, the prevalence of moderate ones were $26 \%$ in boys, but $6.2 \%$ in girls.

In contrast, the percentage of slight sexual relationship and attitude was $92 \%$ in female students which was higher than in male ones (66.4\%), the prevalence rates of high violence among male and female students were $5.50 \%$ and $1.40 \%$, respectively. The prevalence rates of smoking among male and female students were $6.80 \%$ and $2.50 \%$, respectively. The prevalence rates of high drug use among male and female students were $8.90 \%$ and $2.40 \%$, respectively. The prevalence rates of drinking among male and female students were $5.40 \%$ and $1.60 \%$, respectively. In contrast, the percentage of slight drinking was lower in girls (89.20\%) compared to boys (72.30\%).

Based on the results of the Chi-square test, as the significance level of the calculated Chi-square is less than 0.05 , risky driving $\left(P<0.015, d f=2, \chi^{2}=6.170\right)$, sexual relationship and attitude $\left(P<0.015, d f=2, \chi^{2}=83.214\right)$, violence $\left(P<0.001, d f=2, \chi^{2}=23.650\right)$, smoking $(P<0.001$, $\left.d f=2, \chi^{2}=12.320\right)$, drug use $\left(P<0.001, d f=2, \chi^{2}=17.325\right)$ and drinking $\left(P<0.001, d f=2, \chi^{2}=37.646\right)$. The difference in frequency percentage distribution of the studied subjects based on the level of risky driving, sexual relationship and attitude, violence, smoking, drug use and drinking is significant and higher in male students than in female.

As seen in the Table 3, the mean observed scores of all high-risk behaviors among medical students are less than the expected mean. Also, because of the significant level of $t(P<0.01)$, the mean difference was significant except for the mean score of and sexual relationship and attitude $(P>0.05)$. It can be said that the prevalence rates of risky driving, violence, smoking, drug use and drinking in Hamadan medical students are less than average, and the sexual relationship and attitude among these students is at moderate level.

The Table 4 presents a significant relationship between age and education with dangerous driving and

Table 1. The descriptive statistics of risky behaviors

\begin{tabular}{ccccc}
\hline Risky Behavior & Min & Max & Mean \pm SD & $2.86 \pm 0.68$ \\
\hline Risky driving & 1 & 5 & $2 \pm 1.09$ & 43.60 \\
Violence & 1 & 5 & $1.61 \pm 0.85$ & 32.20 \\
\hline Smoking & 1 & 5 & $1.33 \pm 0.51$ & 26.60 \\
\hline Drug use & 1 & 5 & $1.57 \pm 0.78$ \\
\hline Drinking & 1 & 5 & $2.43 \pm 1.09$
\end{tabular}


Table 2. The frequency distribution based on risky behavior

\begin{tabular}{|c|c|c|c|c|c|c|c|c|c|c|c|}
\hline \multirow{2}{*}{\multicolumn{2}{|c|}{ Variables }} & \multirow{3}{*}{$\begin{array}{c}\begin{array}{c}\text { Scores } \\
\text { Ranges F }\end{array} \\
6-13\end{array}$} & \multicolumn{2}{|c|}{ Male } & \multicolumn{2}{|c|}{ Female } & \multicolumn{2}{|c|}{ Total } & \multirow{3}{*}{$x^{2}$} & \multirow{3}{*}{ df } & \multirow{3}{*}{ sig. } \\
\hline & & & \multirow{2}{*}{$\begin{array}{c}P \\
46\end{array}$} & \multirow{2}{*}{$\begin{array}{c}\mathbf{F} \\
15.70\end{array}$} & \multirow{2}{*}{$\begin{array}{l}\mathbf{P} \\
96\end{array}$} & \multirow{2}{*}{$\begin{array}{c}\mathbf{F} \\
19.20\end{array}$} & \multirow{2}{*}{$\begin{array}{c}\mathbf{P} \\
142\end{array}$} & \multirow{2}{*}{$\begin{array}{c}\mathbf{F} \\
18\end{array}$} & & & \\
\hline & Slight & & & & & & & & & & \\
\hline$\sum_{i}^{\bar{\Sigma}}$ & Moderate & $14-21$ & 193 & 66.10 & 339 & 68.10 & 532 & 67.33 & \multirow{3}{*}{6.170} & \multirow{3}{*}{2} & \multirow{3}{*}{0.015} \\
\hline$\frac{\vec{v}}{n}$ & High & $22-30$ & 53 & 18.20 & 63 & 12.70 & 116 & 14.70 & & & \\
\hline & Total & $6-30$ & 292 & 100 & 498 & 100 & 790 & 100 & & & \\
\hline \multirow{4}{*}{ 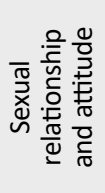 } & Slight & $4-9$ & 194 & 66.40 & 458 & 92 & 652 & 82.50 & \multirow{4}{*}{83.214} & \multirow{4}{*}{2} & \multirow{4}{*}{0.001} \\
\hline & Moderate & $10-15$ & 76 & 26 & 31 & 6.20 & 107 & 13.30 & & & \\
\hline & High & $16-20$ & 22 & 7.60 & 9 & 1.80 & 31 & 3.90 & & & \\
\hline & Total & $4-20$ & 292 & 100 & 498 & 100 & 790 & 100 & & & \\
\hline \multirow{4}{*}{ 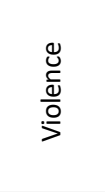 } & Slight & $5-11$ & 174 & 59.60 & 370 & 74.30 & 544 & 68.90 & \multirow{4}{*}{23.650} & \multirow{4}{*}{2} & \multirow{4}{*}{0.001} \\
\hline & Moderate & $12-18$ & 102 & 34.90 & 121 & 24.30 & 223 & 28.20 & & & \\
\hline & High & $19-25$ & 16 & 5.50 & 7 & 1.40 & 23 & 2.90 & & & \\
\hline & Total & $5-25$ & 292 & 100 & 498 & 100 & 790 & 100 & & & \\
\hline \multirow{4}{*}{ 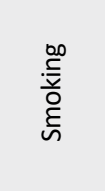 } & Slight & 5-11 & 226 & 77.40 & 426 & 85.50 & 652 & 82.50 & \multirow{4}{*}{12.320} & \multirow{4}{*}{2} & \multirow{4}{*}{0.001} \\
\hline & Moderate & $12-18$ & 46 & 15.80 & 60 & 12 & 106 & 13.40 & & & \\
\hline & High & $19-25$ & 20 & 6.80 & 12 & 2.50 & 32 & 4.10 & & & \\
\hline & Total & $5-25$ & 292 & 100 & 498 & 100 & 790 & 100 & & & \\
\hline \multirow{4}{*}{ 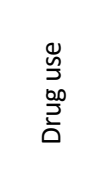 } & Slight & 8-18 & 264 & 90.40 & 448 & 97.20 & 748 & 94.70 & & & \\
\hline & Moderate & $19-29$ & 26 & 8.90 & 12 & 2.40 & 38 & 4.80 & & & \\
\hline & High & $30-40$ & 2 & 0.70 & 2 & 0.40 & 4 & 0.50 & $17.3<3$ & 2 & 0.001 \\
\hline & Total & $8-40$ & 292 & 100 & 498 & 100 & 790 & 100 & & & \\
\hline & Slight & $6-13$ & 211 & 72.30 & 444 & 89.20 & 655 & 89.20 & & & \\
\hline 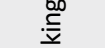 & Moderate & $14-21$ & 65 & 22.30 & 46 & 9.20 & 111 & 14.10 & 16 & 2 & 1 0 \\
\hline 高 & High & $22-30$ & 16 & 5.40 & 8 & 1.60 & 24 & 3 & 40 & 2 & 0.001 \\
\hline & Total & $6-30$ & 292 & 100 & 498 & 100 & 790 & 100 & & & \\
\hline
\end{tabular}

AJNPP

violence; both age and education are negatively related to dangerous driving and violence $(P<0.05)$. This means that with increasing age and education, high-risk behaviors reduce.
According to the Table 4, the correlations between all variables are positive and significant. The relationship between violence, drinking and smoking are positive $(P<0.01)$, which indicated that the higher the level of violence will increase the tendency towards smoking,

Table 3. One sample t-test results for the prevalence of risky behavior

\begin{tabular}{|cccccccc}
\hline Variables & Observed Mean \pm SD & Expected Mean & Mean Difference & t & df & Sig. \\
\hline Risky driving & $17.19 \pm 4.08$ & 15 & 2.19 & 15.102 & 789 & 0.001 \\
\hline Sexual behavior & $9.76 \pm 4.39$ & 10 & 0.24 & 1.562 & 789 & 0.119 \\
\hline Violence & $10.02 \pm 3.71$ & 12.50 & 2.48 & 18.776 & 789 & 0.001 \\
\hline Smoking & $8.09 \pm 4.25$ & 12.50 & 4.41 & 29.104 & 789 & 0.001 \\
\hline Drug use & $10.61 \pm 4.07$ & 20 & 9.39 & 64.8 & 789 & 0.001 \\
\hline Drinking & $9.42 \pm 4.71$ & 15 & 5.57 & 33.340 & 789 & 0.001 \\
\hline
\end{tabular}


Table 4. The correlation between age, education, and risky behavior $(n=790)$

\begin{tabular}{|c|c|c|c|c|c|c|}
\hline Variables & Dangerous Driving & Sexual Behavior & Violence & Smoking & Drug Use & Drinking \\
\hline Age & $-0.168^{*}$ & 0.063 & $-0.084^{* *}$ & 0.022 & -1.16 & -0.044 \\
\hline Education & $-0.174^{*}$ & -0.017 & $0.15^{*}$ & -0.0013 & -0.023 & -0.039 \\
\hline Risky driving & 1 & $0.259 *$ & $0.352^{*}$ & 0.258 & $0.304^{*}$ & $0.298^{*}$ \\
\hline Sexual behavior & $0.259^{*}$ & 1 & $0.338^{*}$ & $0.486^{*}$ & $0.544^{*}$ & $0.648^{*}$ \\
\hline Violence & $0.352^{*}$ & $0.338^{*}$ & 1 & $0.433^{*}$ & $0.441^{*}$ & $0.410^{*}$ \\
\hline Smoking & $0.258^{*}$ & $0.486 *$ & $0.443^{*}$ & 1 & $0.583^{*}$ & $0.626^{*}$ \\
\hline Drug use & $0.304^{*}$ & $0.544^{*}$ & $0.410^{*}$ & $0.583^{*}$ & 1 & $0.705^{*}$ \\
\hline Drinking & $0.298^{*}$ & $0.648 *$ & $0.410^{*}$ & $0.626^{*}$ & $0.705^{*}$ & 1 \\
\hline
\end{tabular}

drinking, and drug use. Moreover, sexual relationship and attitude are positively related to drinking and drug use $(P<0.01)$.

As the results show, some high-risk behaviors have a moderate prevalence among medical students. It is noteworthy that due to limitations of self-report research, the results should be considered as minimum and undoubtedly the actual prevalence of such behaviors among students is higher than the figures listed.

\section{Discussion}

Risky driving is one of the leading causes of road accidents and significantly related to mortality rate. According to the WHO, road accidents account for 1.2 million deaths per year [13] and vehicle-related incidents are one of the leading causes of death and disability in the age group of 10-24 years [13]. Accidents not only cause personal injury or death but also produce the relative's anxiety, financial costs, and other problems. The disabilities caused by accidents eventually end in more difficult and complicated situations.

Risk-taking youth along with other behavioral factors such as lack of experience, desire to express independence and courage, unhealthy environment and risk-seeking excitability can increase the risky driving behaviors in adolescents and youth [13]. As the results suggest, the mean score of risky driving was 2.86 (53.64\%), specifically $18.2 \%$ in boys and $12.7 \%$ in girls. According to the Chi-square test results, the prevalence of dangerous driving is significantly higher in male students. The results of this study are consistent with the findings of Chang et al. $(2007,2011)[6,9,14,15]$.
Youth violence is a significant public health problem [16]. Violence in youth can create mental disorders in their relatives. Violence can take many forms such as physical force, damaging somebody or something and doing risky behavior such as unprotected sex, smoking, drinking and so on [17]. Auerbach et al. (2007) also found out that adolescents with high levels of violence use maladaptive coping styles [18]. In this research, the mean scores of violence were 2 (40\%), and the average violence rate was $34.9 \%$ in boys and $24.3 \%$ in girls. This finding is consistent with other research results $[17,19]$. Regarding this finding, awareness of parents, educators, and teachers of the characteristics of youth and adolescents and the traumatic factors, can be useful in preventing high-risk behaviors.

All over the world, smoking, alcohol, and drug consumption are the leading and preventable causes of death; most adult smokers start smoking since the young age [20]. The research of Mangerud et al. (2014) indicated that the prevalence of smoking was $20.30 \%$ and the prevalence of smoking in boys and girls varies across the countries. For example in Norway, girls are reported to smoke more although boys start smoking earlier [20]. The mean scores of smoking in this research was 1.61 (32.20\%), and the moderate smoking in boys and girls was $15.8 \%$ and $12 \%$, respectively. The findings of Momen Nasab et al. (2005) show that $25 \%$ of studied subjects have experienced smoking before [21].

In Europe, $11-57 \%$ of boys and $12-67 \%$ of girls are smokers; the results indicate that the percentage of addiction was $0.7 \%$ in boys and $0.4 \%$ in girls. On the other hand, the moderate addiction rates in male and female students were believed to be $8.9 \%$ and $2.4 \%$, respectively. Thus, it can be seen that in both cases, 
boys are more likely to consume substances [21]. Alcohol consumption among adolescents and young adults seem to be increasing [22]. Moreover, men drink more alcohol than women [23].

Mangerud et al. (2014) reported that the prevalence of alcohol and drug use was $45.90 \%$ and $12.70 \%$, respectively [20]. The mean scores of drinking and drug use in this research were $1.57(31.40 \%)$ and $1.33(26.60 \%)$, respectively. Drug use and alcohol consumption among Iranian population seem to be lower than other countries which might be because of the religious prohibition of alcohol in our country. Furthermore, a study conducted in Sweden revealed that alcohol consumption in the Middle East, including Iran, is lower compared to other countries [24].

The Population Council reported that young people face many concerns regarding sexual and reproductive health such as sexually transmitted diseases, unwanted pregnancies, HIV and AIDS [25]. These health complications get worse because of the lack of knowledge, services, and poor education [26]. Boys are more likely to engage in high-risk sexual behaviors than girls [27]. In the report of Kann et al. (2014) $34.0 \%$ of the study subjects had sexual intercourse within the three months before the survey [28].

The mean score of sexual relationship and attitude in this research was 2.43 (48.60\%). The moderate prevalence rates of sexual relationship and attitude were $26.34 \%$ and $6.20 \%$ in boys and girls, respectively. Similar studies conducted in Iran and other countries have alerted authorities about the alarming outbreak of these relationships in adolescents and youth [28]. Studies have shown that half of HIV infections occur in adolescents and youth [29-32].

Another finding of the present study showed the relationship between age and education with dangerous driving and violence; both age and education are negatively related to dangerous driving and violence which indicates that with increasing age and education, highrisk behaviors will reduce. The correlations between all variables are positive and significant. The relationship between violence, drinking, and smoking is positive, indicating that the higher the level of violence would increase the tendency to smoking, drinking, and drug use. Moreover, sexual relationship and attitude are positively related to drinking and drug use.

This finding is consistent with other research studies $[13,33,34]$. Furthermore, a significant positive relationship was found between violence, alcohol consumption and smoking which shows that with higher level of vio- lence, the tendency towards consuming cigarette, alcohol, and substances increases and vice versa which was also consistent with the results obtained from earlier research [35]. Moreover, opposite-sex sexual relation and behavior were positively related to alcohol consumption. There was also a significant positive relationship between sexual relation and smoking, alcohol consumption, and substance abuse which was in line with the findings of previous studies [33, 36, 37].

\section{Conclusion}

Unprotected sex has already sounded the alarm for the spread of sexually transmitted infections, particularly AIDS and hepatitis. Providing facilities for youth marriage as well as informing students about high-risk behaviors in schools and universities could play an essential role in preventing those behaviors.

Based on the results, the scores of all high-risk behaviors in male students of Hamadan University of Medical Sciences are higher than female students. In addition, considering the significance level of $t(P<0.05)$, the prevalence of all high-risk behaviors (dangerous driving, violence, smoking, substance abuse, alcohol consumption, sexual relation, and opposite-sex friendship) in male students are significantly higher than female ones which suggest that boys are more liable to high-risk behaviors Thus, it is essential to pay close attention to this vital issue. Our study limitation was using only the samples from newly-admitted university students that affect the external validity and generalization of the results.

\section{Ethical Considerations}

\section{Compliance with ethical guidelines}

The study was approved by the Ethics Committee of Hamadan University of Medical Sciences (No.: IR.UMSHA.REC.1395.414). Written consent was taken from each student.

\section{Funding}

This study was supported by Hamadan University of Medical Sciences (project No.: 9511126841).

\section{Authors contributions}

Study design, protocol writing, cell preparation, data collection, analysis interpretations: Marzieh Nazaribadie; Interpretation: Amir Keshavarzi, Mohammad Ah- 
madpanah, Ali Ghaleiha; and Writing, reviewing, reading and approving the manuscript: All authors.

\section{Conflict of interest}

The authors declared no conflict of interest.

Acknowledgements

The authors express their appreciation to the students of Hamadan University of Medical Sciences.

\section{References}

[1] Vakilian K, Mousavi SA, Keramat A. Estimation of sexual behavio in the 18-to-24-years-old Iranian youth based on a crosswise model study. BMC Research Notes. 2014; 7(1):28. [DOI:10.1186/17560500-7-28] [PMID] [PMCID]

[2] Brown JL, Vanable PA. Alcohol use, partner type, and risky sexual behavior among college students: Findings from an event-level study. Addictive Behaviors. 2007; 32(12):2940-52. [DOI:10.1016/j. addbeh.2007.06.011] [PMID] [PMCID]

[3] Sher L, Zalsman G. Alcohol and adolescent suicide. International Journal of Adolescent Medicine and Health. 2005; 17(3):197-203. [PMID]

[4] Negeri EL. Assessment of risky sexual behaviors and risk perception among youths in western Ethiopia: The influences of family and peers: A comparative cross-sectional study. BMC Public Health. 2014; 14(1):301. [DOI:10.1186/1471-2458-14-301] [PMID] [PMCID]

[5] Ferguson CJ, San Miguel C, Hartley RD. A multivariate analysis of youth violence and aggression: The influence of family, peers, depression, and media violence. The Journal of pediatrics. 2009; 155(6):904-8. [DOI:10.1016/j.jpeds.2009.06.021] [PMID]

[6] Fergusson D, Swain-Campbell N, Horwood J. Risky driving behaviour in young people: Prevalence, personal characteristics and traffic accidents. Australian and New Zealand Journal of Public Health. 2003. 27(3):337-42. [DOI:10.1111/j.1467-842X.2003.tb00404.x] [PMID]

[7] Vassallo S, Smart D, Sanson A, Cockfield S, Harris A, Mclntyre A, et al. Risky driving among young Australian drivers II: Co-occurrence with other problem behaviours. Accident Analysis \& Prevention. 2008; 40(1):376-86. [DOI:10.1016/j.aap.2007.07.004] [PMID]

[8] Abayomi O, Babalola OR, Olakulehin OA, Ighoroje M. Drink driving and risky behavior among university students in southwestern $\mathrm{Ni}$ geria-Implications for policy development. Traffic Injury Prevention. 2016; 17(4):330-5. [DOI:10.1080/15389588.2015.1077238] [PMID]

[9] Scott Parker B, Watson B, King MJ. Understanding the psychosocial factors influencing the risky behavior of young drivers. Transportation Research Part F: Traffic Psychology and Behaviour. 2009; 12(6):470-82. [DOI:10.1016/j.trf.2009.08.003]

[10] Bergman MM, Scott J. Young adolescents' wellbeing and health-risk behaviors: Gender and socio-economic differences. Journal of Adolescence. 2001; 24(2):183-97. [DOI:10.1006/jado.2001.0378] [PMID]

[11] Lindberg LD, Boggess S, Williams S. Multiple threats: The CoOccurrence of teen health risk behaviors. Washington, D.C.: United
States Department of Health and Human Services, Office of the Assistant Secretary for Planning and Evaluation; 2000.

[12] Zadeh Mohammadi A, Ahmadabadi Z, Panaghi L, Heidari M. [Validity and reliability of Iranian Youth risk-taking scale (Persian)]. Journal of Psychology. 2011; 15(2):129-46.

[13] Abayomi O, Babalola O, Olakulehin O, Ighoroje M. Drink driving and risky behavior among university students in southwestern $\mathrm{Ni}$ geria-implications for policy development. Traffic Injury Prevention. 2016; 17(4):330-5. [DOI:10.1080/15389588.2015.1077238] [PMID]

[14] Chung YS, Wong JT. Beyond general behavioral theories: Structural discrepancy in young motorcyclist's risky driving behavior and its policy implications. Accident Analysis \& Prevention. 2012; 49:16576. [DOI:10.1016/j.aap.2011.04.021] [PMID]

[15] Chang HL, Yeh TH. Motorcyclist accident involvement by age gender, and risky behaviors in Taipei, Taiwan. Transportation Research Part F: Traffic Psychology and Behavior. 2007; 10(2):109-22. [DOI:10.1016/j.trf.2006.08.001]

[16] Duke NN, Borowsky IW. Youth violence prevention and safety: Opportunities for health care providers. Pediatric Clinics of North America. 2015; 62(5):1137-58. [DOI:10.1016/j.pcl.2015.05.009] [PMID]

[17] Martinez J, Hosek SG, Carleton RA. Screening and assessing violence and mental health disorders in a cohort of inner city HIV-positive youth between 1998-2006. AIDS Patient Care and Stds. 2009; 23(6):469-75. [DOI:10.1089/apc.2008.0178] [PMID] [PMCID]

[18] Auerbach RP, Abela JR, Zhu X, Yao S. A diathesis-stress model of engagement in risky behaviours in Chinese adolescents. Behaviour Research and Therapy. 2007; 45(12):2850-60. [DOI:10.1016/j. brat.2007.05.005] [PMID]

[19] Resnick MD, Ireland M, Borowsky I. Youth violence perpetration: What protects? What predicts? Findings from the National Longitudinal Study of Adolescent Health. Journal of Adolescent Health. 2004; 35(5):424.e1-.e10. [DOI:10.1016/j.jadohealth.2004.01.011] [PMID]

[20] Mangerud WL, Bjerkeset O, Holmen TL, Lydersen S, Indredavik MS. Smoking, alcohol consumption, and drug use among adolescents with psychiatric disorders compared with a population based sample. Journal of Adolescence. 2014; 37(7):1189-99. [DOI:10.1016/j.adolescence.2014.08.007] [PMID]

[21] Momennasab M, Najafi SS, Kave MH, Ahmadpoor F. [[Prevalence the harmful behaviours among university students in Khorramabad City, 2004-2005 (Persian)]. Yafteh: Journal of Lorestan University of Medical Sciences. 2006; 8(2):23-9.

[22] World Health Organization. Global status report on alcohol and health, 2011. Geneva: World Health Organization; 2011.

[23] Kerr Corrêa F, Igami TZ, Hiroce V, Tucci AM. Patterns of alcohol use between genders: A cross-cultural evaluation. Journal of Affective Disorders. 2007; 102(1-3):265-75. [DOI:10.1016/j. jad.2006.09.031] [PMID]

[24] Bulloock S, Room R. Alcohol consumption by adolescents and young adults. Paper presented at: $30^{\text {th }}$ Annual Alcohol Epidemiology Symposium of the Kettil Bruun Society for Social and Epidemiological Research on Alcohol. 31 May-4 June, 2004; Helsinki, Finland.

[25] Commission ZA. The adolescent experience in-depth: Using Data to identify and reach the most vulnerable young people: Tanzania 2009-2012. New York: Population Council; 2015 
[26] Lopez JR, Mukaire PE, Mataya RH. Characteristics of youth sexual and reproductive health and risky behaviors in two rural provinces of Cambodia. Reproductive Health. 2015; 12(1):83. [DOI:10.1186/ s12978-015-0052-5] [PMID] [PMCID]

[27] Sasson H, Mesch G. Gender differences in the factors explaining risky behavior online. Journal of Youth and Adolescence. 2016; 45(5):973-85. [DOI:10.1007/s10964-016-0465-7] [PMID]

[28] Kann L, Kinchen S, Shanklin SL, Flint KH, Hawkins J, Harris WA, et al. Youth risk behavior surveillance-United States, 2013. Morbidity and Mortality Weekly Report: Surveillance Summaries. 2014; 63(4):1-168. [PMID]

[29] Taffa N. Sexual activity of out-of-school youth, and their knowledge and attitude about STDs and HIV/AIDS in Southern Ethiopia. Age (yrs). 1998; 15(17):72.

[30] Gong E. HIV testing and risky sexual behavior. The Economic Journal. 2015; 125(582):32-60. [DOI:10.1111/ecoj.12125]

[31] Abram KM, Stokes ML, Welty L, Aaby DA, Teplin LA. Disparities in HIV/AIDS risk behaviors after youth leave detention: A 14-year longitudinal study. Pediatrics. 2017; 139(2):e20160360. [DOI:10.1542/ peds.2016-0360] [PMID] [PMCID]

[32] Yadav D, Chakrapani V, Goswami P, Ramanathan S, Ramakrishnan L, George B, et al. Association between alcohol use and HIV-related sexual risk behaviors among men who have sex with men (MSM) findings from a multi-site bio-behavioral survey in India. AIDS and Behavior. 2014; 18(7):1330-8. [DOI:10.1007/s10461-014-0699-x] [PMID] [PMCID]

[33] Cooper ML. Alcohol use and risky sexual behavior among college students and youth: Evaluating the evidence. Journal of Studies on Alcohol Supplement. 2002; (14):101-17. [DOI:10.15288/jsas.2002. s14.101] [PMID]

[34] MacArthur G, Smith M, Melotti R, Heron J, Macleod J, Hickman $\mathrm{M}$, et al. Patterns of alcohol use and multiple risk behaviour by gender during early and late adolescence: The ALSPAC cohort. Journal of Public Health. 2012; 34(1):20-30. [DOI:10.1093/pubmed/fds006] [PMCID] [PMID]

[35] Turner CF, Ku L, Rogers SM, Lindberg LD, Pleck JH, Sonenstein FL. Adolescent sexual behavior, drug use, and violence: Increased reporting with computer survey technology. Science. 1998; 280(5365):867-73. [DOI:10.1126/science.280.5365.867] [PMID]

[36] Leigh BC, Stall R. Substance use and risky sexual behavior for exposure to HIV: Issues in methodology, interpretation, and prevention. American Psychologist. 1993; 48(10):1035-45. [DOI:10.1037/0003066X.48.10.1035]

[37] Benotsch EG, Snipes DJ, Martin AM, Bull SS. Sexting, substance use, and sexual risk behavior in young adults. Journal of Adolescent Health. 2013; 52(3):307-13. [DOI:10.1016/j.jadohealth.2012.06.011] [PMID] [PMCID] 